\title{
Neurointensive care results and risk factors for unfavorable outcome in aneurysmatic SAH: a comparison of two age groups
}

\author{
Vilja Välimäki ${ }^{1}$ - Teemu Luostarinen ${ }^{2} \cdot$ Jarno Satopää $^{1} \cdot$ Rahul Raj $^{1} \cdot$ Jyri J. Virta ${ }^{1}$ (D)
}

Received: 10 December 2020 / Accepted: 21 January 2021 / Published online: 29 January 2021

(C) The Author(s) 2021

\begin{abstract}
Background The mean age of actively treated subarachnoid hemorrhage (SAH) patients is increasing. We aimed to compare outcomes and prognostic factors between older and younger SAH patients.

Methods A retrospective single-center analysis of aneurysmal SAH patients admitted to a neuro-ICU during 2014-2019. We defined older patients as $\geq 70$ years and younger patients as $<70$ years. For every older patient, we identified three younger patients with the same World Federation of Neurological Surgeons (WFNS) grade. We only included patients receiving active aneurysm treatment. Favorable functional outcome, defined as a Glasgow Outcome Scale (GOS) of 4-5 at 12 months, was our primary outcome. We used logistic regression to compare prognostic factors between the groups.

Results Ninety-five (85\%) of 112 older patients and 317 (94\%) of 336 younger patients received aneurysm treatment. Of the younger patients, $91 \%$ with a good-grade SAH (WFNS I-III) had a favorable outcome compared to $52 \%$ in the older good-grade SAH group. In poor-grade patients (WFNS IV-V), favorable outcome was seen in $51 \%$ of younger patients, compared to $24 \%$ of older patients. Acute hydrocephalus and intracerebral hemorrhage were associated with unfavorable outcome in the younger (OR 4.7, 95\% CI 2.6-8.4, and OR 3.7, 95\% CI 2.1-6.4), but not in the older patients (OR 1.8, 95\% CI 0.8-4.2, and OR 1.3, 95\% CI $0.5-3.1$, respectively).

Conclusions In actively treated SAH patients, age was a major determinant of outcome. Factors reflecting increases in intracranial pressure associated with outcome only among younger patients.
\end{abstract}

Keywords Subarachnoid hemorrhage $\cdot$ Prognosis $\cdot$ Elderly $\cdot$ Risk factor

\section{Introduction}

The increasing number of elderly people with good functional capacity has led to an increase in the number of elderly patients treated at intensive care units (ICU) $[1,11]$. As a

This article is part of the Topical Collection on Neurosurgical Intensive Care

The work has not been presented e.g. at a conference.

Teemu Luostarinen and Jarno Satopää contributed equally to this work.

Jyri J. Virta

jyri.virta@hus.fi

1 Department of Neurosurgery, Helsinki University Hospital and University of Helsinki, Helsinki, Finland

2 Division of Anesthesiology, Department of Anesthesiology, Intensive Care and Pain Medicine, University of Helsinki and Helsinki University Hospital, Helsinki, Finland vascular disorder with lifelong modifiable risk factors [2, 18], subarachnoid hemorrhage (SAH) has been shown to reach its peak incidence at 70-75 years of age [17]. Therefore, the number of elderly patients with SAH treated at neuro-ICUs is increasing.

Few studies have compared outcomes between younger and older SAH patients $[4,26]$ or compared prognostic factors between age groups [6]. Additionally, two landmark studies on prognostic factors of hospitalized patients with aneurysmatic SAH (aSAH) have included relatively young patients with mean ages of 58 and 53 years, respectively [13,24]. Additionally, in these studies, none or a minority of aneurysms received endovascular treatment, whereas today, endovascular treatment is selected in up to two thirds of aneurysms [14].

Our aim was to compare the outcomes of younger and older aSAH patients admitted to a neuro-ICU in an institution where most ruptured aneurysms receive endovascular treatment and to assess whether the prognostic factors for functional outcome and mortality at 12 months differ between the 
age groups. We chose 70 years of age as the cut-off point. We hypothesized that older age is an independent risk factor for poor outcome and mortality even when comparing patients with similar SAH severity.

\section{Methods}

\section{Study setting and population}

We conducted a single-center retrospective study of consecutive aSAH patients admitted to the neuro-ICU of the Helsinki University Hospital. The Helsinki University Hospital covers a population of approximately 2 million people. Finland's health care system offers equal and low-cost public health care for all citizens regardless of e.g. income or insurance status. The neuro-ICU at Helsinki University Hospital is the only ICU providing neurosurgical and neurointensive care for citizens living in the hospital's catchment area. Thus, all actively treated aSAH patients are transferred to the designated neuro-ICU.

We screened all patients admitted to the neuro-ICU and identified those with an International Statistical Classification of Diseases and Related Health Problems (ICD) 10 code of I60.0-I60.9 (including non-traumatic SAH from specific arteries and unspecified non-traumatic SAH) between January 2014 and May 2019. We then evaluated all patients and included only those with a verified aSAH and excluded those with other disorders.

We then identified all $\geq 70$-year-old patients with an available World Federation of Neurological Surgeons (WFNS) grade [7], excluding those who were initially admitted to the neuro-ICU only as potential organ donors. For every $\geq 70$-yearold patient, we randomly selected three $<70$-year-old patients with a matching WFNS grade (i.e., 1:3 matching). This resulted in two groups of patients with an equal distribution of SAH severity, according to the WFNS grade. We refer to the $\geq 70$ year-old patients as the older group and to the $<70$ years old as the younger group. A study flow chart is shown in Fig. 1.

\section{Data collection}

After selecting patients to both groups, we scrutinized electronic health records and imaging data to extract the following variables: age at admission, Charlson Comorbidity Index (CCI) [5], use of antithrombotic medication (antiplatelets or anticoagulants), time from ictus to admission $(<12 \mathrm{~h}, 12-24 \mathrm{~h}$ or $>24 \mathrm{~h}$ ), SAH severity using WFNS grading scale, location of the ruptured aneurysm (anterior or posterior circulation), aneurysm size, aneurysm treatment modality (surgical or endovascular), discharge unit from the neuro-ICU (step-down unit or ward), and presence of acute hydrocephalus requiring treatment with an external ventricular drain (EVD). For those patients who were intubated before admission at our hospital,
872 adult patients admitted to neuro-ICU with ICD-10 diagnoses 160.0-160.9 between Jan 2014 and May 2019 screened

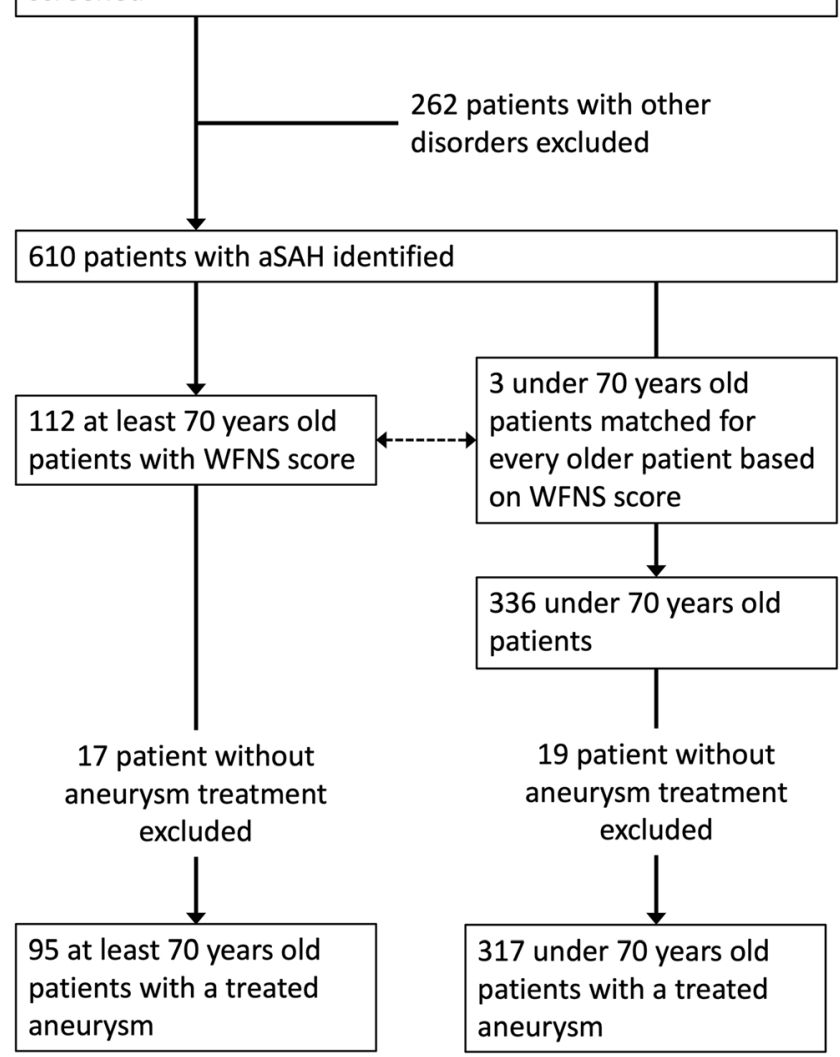

Fig. 1 Study flow-chart. ICD-10: International Classification of Diseases. WFNS: World Federation of Neurological Surgeons scale

we used the last recorded Glasgow Coma Scale (GCS) [27] score to estimate the WFNS grade.

From the admission computed tomography (CT) scan, we evaluated the presence of a thick and diffuse bleeding pattern (clot thickness $\geq 4 \mathrm{~mm}$ in $\geq 3$ cisterns), any intraventricular hemorrhage (IVH) regardless of volume or number of ventricles affected, and intracerebral hemorrhage (ICH).

Additionally, we collected data on possible development of delayed cerebral ischemia (DCI) or shunt-dependent chronic post-SAH hydrocephalus. We diagnosed DCI based upon clinical symptoms and/or radiological findings. If a patient developed new neurological deficits not attributable to a previous focal lesion with radiological vasospasm on CT angiography (CTA), we initiated DCI treatment (intravenous nimodipine infusion and augmented hypertension) if feasible. If reliable neurological assessment was not possible due to intubation and severe radiological vasospasm was observed, we initiated treatment. If reliable neurological assessment was possible, the presence of radiological vasospasm without clinical findings did often not justify treatment. If a patient developed new CT hypodensities outside the direct vicinity of a previous focal lesion, we considered it a sign of DCI and initiated treatment. 
We classified possible limitation-of-care orders during the stay in the neuro-ICU into three groups: do-not-resuscitate (DNR), weaning of life-supportive care, and treatment as a possible organ donor. Only the gravest limitation was recorded. Finland has an opt-out organ donation policy, with all patients having the possibility to act as organ donors if they are not known to have previously opposed organ donation.

\section{Outcomes}

Our primary outcome was functional outcome at 12 months after aSAH determined retrospectively from expansive communal electronic health records. We defined favorable outcome as Glasgow Outcome Scale (GOS) [15] 4-5 and unfavorable outcome as GOS $1-3$. We also recorded whether the patients were able to live at home (with or without external help) or had to be institutionalized (e.g., in a habilitation facility or hospital) at 12 months. Our secondary outcome was all-cause mortality at 12 months after aSAH.

\section{Statistical analyses}

As age, aneurysm size, and duration of neuro-ICU treatment were not normally distributed (according to Shapiro-Wilk test and visual inspection of histograms), we report median and interquartile range (IQR) values for the continuous variables. For categorical variables, we report frequencies. We divided CCI into three categories: 0,1 , and $\geq 2$ points. For risk factor analyses, we dichotomized SAH severity into good and poor grades (WFNS I-III and WFNS IV-V, respectively). In the outcome and risk factor analyses, we included only patients who had their aneurysm secured.

Due to the matched nature of our data, we used a generalized mixed model when comparing the age groups, using age group as a fixed effect and matching group (including one older patient and three WFNS-matched younger patients) as a random effect.

To assess risk factors for unfavorable outcome and allcause mortality, we performed univariate logistic regression analyses separately for both age groups yielding odds ratios (OR) with $95 \%$ confidence intervals (CI). Reference group for each factor is described in the results. Additionally, to further assess possible interactions between age and the effect of potential risk factors, we performed logistic regression analyses for all patients including a potential risk factor, age group (younger vs. older group), and their interaction term (i.e., risk factor $\times$ age group).

To test whether age was an independent risk factor for unfavorable functional outcome and mortality at 12 months, we performed a multivariate logistic regression analysis on all patients. Based on the univariate analyses and clinical correlation, the multivariate model included CCI, SAH severity, presence of acute hydrocephalus, presence of IVH, presence of ICH, presence of a thick and diffuse SAH, and aneurysm location $[13,24]$. We then added age group to this original model. We report Nagelkerke $R^{2}$ for both models. If age group was significantly associated with outcome in this new model, and if the new model explained more of the variance in the outcome (i.e., if the difference between the Log-likehoods between the models was significant), we considered age group to be independently associated with our outcome.

As we expected there to be few missing values, we excluded those with missing values from the comparison analyses. We considered $p$ values $<0.05$ as statistically significant. As statistical power to detect interactions is lower than for main effects $[3,8]$, we did not use the significance threshold of $p<0.05$ for the interaction term. An age group $\times$ risk factor effect was considered possible, if the ORs differed between the age groups and the $p$ value of the interaction term was $<0.10$.

\section{Ethics approval}

The local institutional research committee approved the study and waived the need for patient consent (HUS/466/2019 $\S 106)$. The study was conducted according to the Strengthening the Reporting of Observational studies in Epidemiology (STROBE) Statement.

\section{Results}

\section{Population characteristics}

Overall, we identified 610 aSAH patients admitted to the neuro-ICU between January 2014 and May 2019. The median age of all patients was 57.8 years (IQR 49.6-67.4). The WFNS distribution of all admitted aSAH patients did not differ between the age groups (Mann-Whitney $U$ test, $p=0.48$ ), and the proportion of poor-grade aSAH patients did not differ between younger and older patients (40\% vs. $40.5 \%$, respectively, $p=0.96)$. The mean age of patients did not change during the study period ( $p=0.87$ ).

After excluding 4 patients who were initially admitted as potential organ donors, there were 112 patients over the age of 70 years with available WFNS data. Hence, 336 patients under the age of 70 years were selected for the analyses matching for WFNS grade.

Seventeen $(15 \%)$ of 112 patients in the older group did not have their aneurysm secured because the treating clinicians regarded their prognosis too poor. In contrast, only $19(6 \%)$ of 336 patients in the younger group did not have their aneurysm secured. The difference between the groups was significant $(p=0.002)$. Overall, this left 412 patients for our analyses (317 in the younger group and 95 in the older group). The study flow chart is shown in Fig. 1. 


\section{Group characteristics}

Even after excluding patients whose aneurysm was not secured, the WFNS distribution was similar between the age groups. The median age was 55 years (IQR 48-63) in the younger group, and 75 years (IQR 72-80) in the older group (difference between groups significant, $p<0.001$ ). The older patients were more often women, had a higher CCI score, and were more often on antiplatelet or anticoagulant medication. Additionally, they were more likely to have a thick and diffuse bleeding pattern. There was no difference in the presence of acute hydrocephalus, ICH, or IVH between the groups.

The age groups did not differ in aneurysm location, size (median maximal diameter 6.0 mm [IQR 5.0-9.0] in the younger group, and $6.0 \mathrm{~mm}$ [IQR 4.0-9.0] in the older group, $p=$ 0.99 ), or treatment modality.

When considering only the 404 patients alive after 1 week, DCI was more often diagnosed and treated in the younger group. Among the 393 patients alive 2 weeks after admission, the older patients were more likely to develop chronic hydrocephalus than younger patients.

Limitation-of-care orders were more common among the older. The duration of neuro-ICU treatment (including possible readmissions) was longer in the younger group (median 12 days, IQR 7-16) than in the older group (median 9 days, IQR $4-15, p<0.001)$. The older patients were more often discharged to a step-down unit instead of a regular ward.

Detailed group characteristics and comparisons are shown in Table 1.

\section{2-month mortality and functional outcome}

Twenty-two (7\%) of the 317 younger patients died during the first 12 months, whereas $26(27 \%)$ of the 95 older patients died $(p<0.001)$.

Twelve-month functional outcome was available for 406 patients. For those alive at 12 months, the follow-up time was shorter in the younger group (median 329 days, IQR 231-389 days, and median 357 days, IQR 295-472 days in the older group, $p<0.001$ ).

Two hundred forty-one (77\%) of the 313 younger patients had a favorable outcome compared to 40 of 93 patients (43\%) in the older group $(p<0.001)$. Of those alive at 12 months, $93 \%$ of the younger patients and $82 \%$ of the older patients were living at home $(p=0.02)$. Detailed functional outcome information is shown in Fig. 2.

\section{Risk factors for unfavorable outcome at $\mathbf{1 2}$ months}

Sex or CCI was not associated with unfavorable outcome in either age group. Poor-grade SAH was associated with unfavorable outcome in both groups, but the association was stronger in the younger patients. Acute hydrocephalus was associated with unfavorable outcome only in the younger group. ICH was associated with unfavorable outcome in the younger group, but not in the older group and the interaction with age group seemed significant. IVH was associated with unfavorable outcome only in the younger group, but the interaction with age group did not seem significant. A thick and diffuse bleeding pattern was not associated with functional outcome in either group.

Surgical aneurysm treatment was associated with unfavorable outcome compared to endovascular treatment in the older group but not in the younger group. The interaction with age group seemed significant. A posterior circulation aneurysm was associated with unfavorable outcome in the younger group compared to an anterior circulation aneurysm, but not in the older group. Still, the interaction with age group was not significant. Results of the risk factor analyses are shown in Table 2.

Among the 398 patients who were alive at 1 week after admission and for whom outcome data was available, DCI was not associated with outcome in either group (OR 1.68, 95\% CI 0.97-2.91 in the younger group, and OR 1.17, 95\% CI $0.45-3.00$ in the older group). Among the 388 patients who were alive at 2 weeks, chronic hydrocephalus was significantly associated with unfavorable outcome only in the younger patients (OR 4.73, 95\% CI 2.60-8.59, and OR 2.50, 95\% CI $0.99-6.33$ in the older group), but the interaction with age group did not seem significant $(p=0.26)$.

\section{Risk factors for a 12-month mortality}

Sex or CCI were not associated with 12-month mortality in either age group. Poor-grade SAH and IVH increased the risk of death in both groups. In contrast, acute hydrocephalus was associated with increased mortality only in the younger group. ICH or a thick and diffuse bleeding pattern was not associated with mortality in either group. In the younger patients, a posterior circulation aneurysm was associated with increased mortality compared to anterior circulation. Aneurysm treatment modality was not associated with mortality in either group.

In the 404 patients alive at 1 week after admission, DCI was not associated with mortality in either group. Likewise, in the 393 patients alive at 2 weeks, chronic hydrocephalus was not associated with mortality in either group. Results of the risk factor analyses for 12-month mortality are shown in Supplemental Table 1.

\section{Effect of age on functional outcome and mortality}

In the multivariate logistic regression model without age group, higher $\mathrm{CCI}$, poor-grade $\mathrm{SAH}$, acute hydrocephalus, $\mathrm{ICH}$, and posterior circulation aneurysm increased the odds of unfavorable outcome at 12 months (Table 3). This model 
Table 1 Demographic, clinical, and radiologic characteristics of the 412 patients included in the study

\begin{tabular}{|c|c|c|c|c|c|}
\hline & \multicolumn{2}{|c|}{ Younger group $(N=317)$} & \multicolumn{2}{|c|}{ Older group $(N=95)$} & \multirow[t]{2}{*}{$p$} \\
\hline & $n$ & $\%$ & $n$ & $\%$ & \\
\hline Sex & & & & & $<0.001$ \\
\hline Women & 187 & 59.0 & 81 & 85.3 & \\
\hline Men & 130 & 41.0 & 14 & 14.7 & \\
\hline Charlson comorbidity index & & & & & $<0.001$ \\
\hline 0 & 253 & 79.8 & 55 & 58.5 & \\
\hline 1 & 47 & 14.8 & 29 & 30.9 & \\
\hline At least 2 & 17 & 5.4 & 10 & 10.6 & \\
\hline Antithrombotic medication & & & & & $<0.001$ \\
\hline None & 298 & 94.0 & 68 & 71.6 & \\
\hline Antiplatelet & 7 & 2.2 & 17 & 17.9 & \\
\hline Anticoagulant & 12 & 3.8 & 10 & 10.5 & \\
\hline Delay from ictus to admission & & & & & 0.15 \\
\hline Under $12 \mathrm{~h}$ & 223 & 70.6 & 59 & 62.1 & \\
\hline $12-24 \mathrm{~h}$ & 22 & 7.0 & 12 & 12.6 & \\
\hline Over $24 \mathrm{~h}$ & 71 & 22.5 & 24 & 25.3 & \\
\hline WFNS scale & & & & & 0.27 \\
\hline I & 120 & 37.9 & 37 & 38.9 & \\
\hline II & 70 & 22.1 & 18 & 18.9 & \\
\hline III & 17 & 5.4 & 10 & 10.5 & \\
\hline IV & 44 & 13.9 & 11 & 11.6 & \\
\hline $\mathrm{V}$ & 66 & 20.8 & 19 & 20.0 & \\
\hline \multicolumn{6}{|l|}{ SAH characteristics } \\
\hline Thick and diffuse clot & 158 & 49.8 & 26 & 27.4 & $<0.001$ \\
\hline Intraventricular hemorrhage & 174 & 54.9 & 59 & 62.1 & 0.20 \\
\hline Intracerebral hemorrhage & 104 & 32.8 & 31 & 32.6 & 0.98 \\
\hline Aneurysm location & & & & & 0.17 \\
\hline Anterior circulation & 275 & 86.8 & 77 & 81.1 & \\
\hline Posterior circulation & 42 & 13.2 & 18 & 18.9 & \\
\hline Treatment modality & & & & & 0.06 \\
\hline Endovascular & 161 & 50.8 & 59 & 62.1 & \\
\hline Surgical & 156 & 49.2 & 36 & 37.9 & \\
\hline \multicolumn{6}{|l|}{ Subarachnoid hemorrhage complications } \\
\hline Acute hydrocephalus & 145 & 45.7 & 53 & 55.8 & 0.08 \\
\hline Delayed cerebral ischaemia ${ }^{a}$ & 156 & 50.0 & 24 & 26.1 & $<0.001$ \\
\hline Chronic hydrocephalus ${ }^{\mathrm{b}}$ & 72 & 23.5 & 31 & 36.0 & 0.02 \\
\hline Limitation-of-care orders & & & & & $<0.001$ \\
\hline None & 299 & 94.3 & 73 & 76.8 & \\
\hline Do-not-resuscitate & 4 & 1.3 & 15 & 15.8 & \\
\hline Weaning of life-supportive care & 8 & 2.5 & 7 & 7.4 & \\
\hline Treated as a potential organ donor & 6 & 1.9 & 0 & 0.0 & \\
\hline Discharge from neurointensive care unit & & & & & $<0.001$ \\
\hline Ward & 207 & 65.5 & 39 & 41.1 & \\
\hline Step-down unit & 101 & 32.0 & 53 & 55.8 & \\
\hline Died at the neuro-ICU & 8 & 2.5 & 3 & 3.2 & \\
\hline Outcome at 12 months ${ }^{\mathrm{c}}$ & & & & & $<0.001$ \\
\hline Favorable outcome & 241 & 77.0 & 40 & 43.0 & \\
\hline Unfavorable outcome & 72 & 23.0 & 53 & 57.0 & \\
\hline
\end{tabular}

${ }^{a}$ Only those alive after 1 week, $n=404$

${ }^{\mathrm{b}}$ Only those alive after 2 weeks, $n=393$

${ }^{c}$ Only those with 12-month outcome data available, $n=406$

WFNS, World Federation of Neurosurgical Societies grading scale 
Fig. 2 Distribution of functional outcomes at 12 months according to Glasgow Outcome Scale. Distributions are shown for all patients and separately for goodgrade (World Federation of Neurological Surgeons scale [WFNS] I-III) and poor-grade (WFNS IV-V) patients. The numbers in the bars indicate the number of patients in each group. Favorable outcome has a green background and unfavorable a red background. a Younger patients (under 70 years of age). b Older patients (at least 70 years of age) a

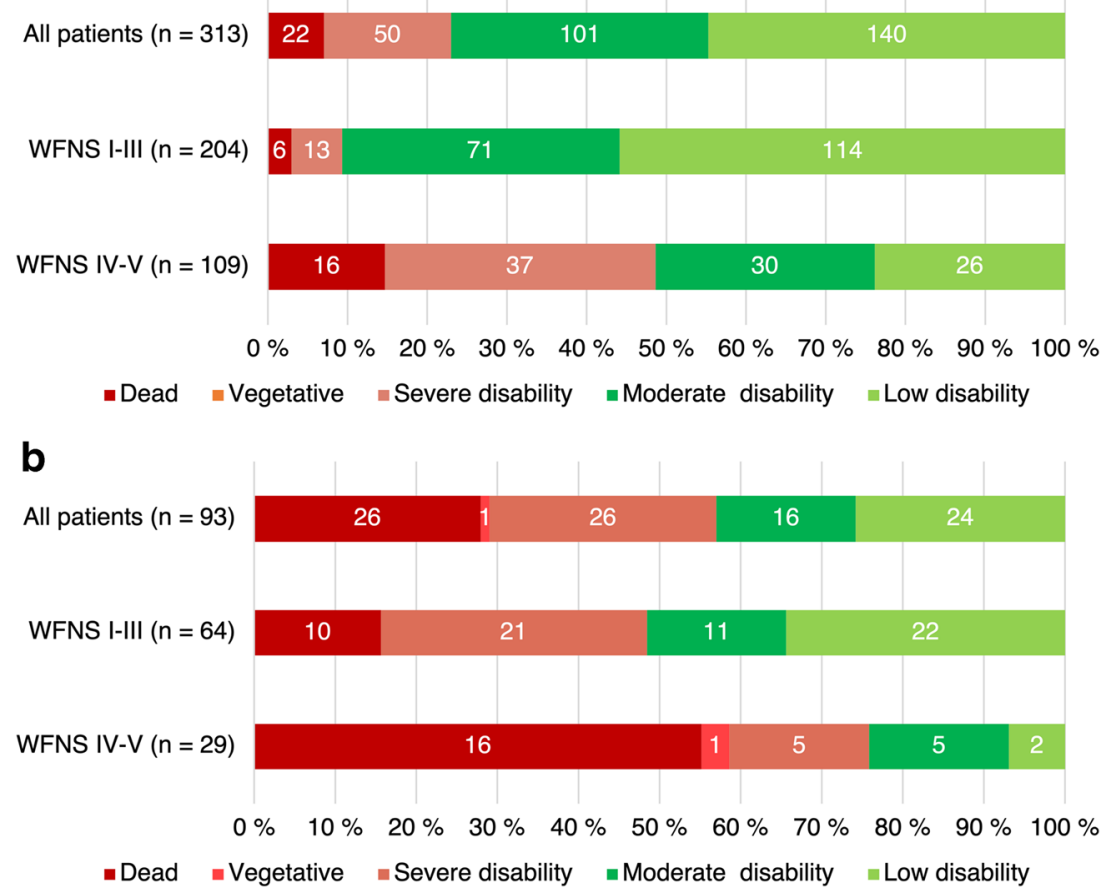

had a Nagelkerke $R^{2}$ value of 0.29 . When we added age group to this model, belonging to the older age group was significantly associated with unfavorable outcome (OR 5.48, 95\% CI 3.0-10.0, see Table 3), and the new model had a Nagelkerke $R^{2}$ of 0.38 . The difference between the Loglikehoods of the models was significant (Chi-square 33.35, $p$ $<0.001$ ), indicating that the new model was a better fit to the data.

Regarding 12-month mortality, the multivariate regression model without age group had a Nagelkerke $\mathrm{R}^{2}$ of 0.22 . Higher $\mathrm{CCI}$, poor-grade SAH, IVH, and a posterior circulation aneurysm were associated with increased risk of death. Adding age group to this model increased the Nagelkerke $R^{2}$ to 0.32 . The older patients had a significantly higher mortality risk when compared to the younger patients (OR 7.0, 95\% CI 3.2-15.3). The difference between the Log-likehoods of the models was significant (Chi-square 26.06, $p<0.001$ ). Detailed results of the multivariate logistic regression analyses regarding $12-$ month mortality are shown in Supplemental Table 2.

\section{Discussion}

\section{Key findings}

In this retrospective, single-center study, we were able to compare younger (under 70 years of age) and older (at least 70 years of age) patients with equal aSAH severity at admission treated at a tertiary center neuro-ICU. All patients received active aneurysm treatment and neurocritical care. In the younger group, $77 \%$ achieved a favorable outcome at 12 months, compared to $43 \%$ of the older group. Likewise, mortality was significantly lower in the younger group (7 vs. $27 \%)$. The prognosis of older good-grade patients matched that of younger poor-grade patients. However, even in the older group, $82 \%$ of survivors were able to live at home at 12 months. Notably, none of the younger patients and only one older patient with poor-grade SAH were in a vegetative state at 12 months.

In multivariate models, the addition of age increased the models' explained variance significantly, and higher age was associated with both increased likelihood of unfavorable outcome as well as death at 12 months. This indicates that older age is an independent risk factor for unfavorable outcome and death at 12 months in hospitalized aSAH patients that receive active treatment.

Being in line with previous reports, the older patients were more often women [20]. Additionally, as indicated by their higher CCI scores, the older patients had more co-morbidities. However, the CCI scores of the older patients were low, suggesting that the patients admitted to our neuro-ICU represented a previously healthy group of elderly people with high preadmission functional reserves. The bleeding pattern was more often thick and diffuse in the older patients, which was to be expected due to their larger cerebrospinal fluid spaces caused by brain atrophy. A thick and diffuse bleeding pattern is regarded a risk factor for DCI [9], but DCI requiring treatment was more seldom seen in the older patients. Some previous 
Table 2 Results of the univariate logistic and interaction analysis for outcome at 12 months after subarachnoid hemorrhage. Proportion of patients with favorable and unfavorable outcomes as well as odds ratios (OR) with $95 \%$ confidence intervals (CI) for unfavorable outcome are shown

\begin{tabular}{|c|c|c|c|c|c|c|c|c|c|}
\hline & \multicolumn{4}{|c|}{ Younger group $(n=313)$} & \multicolumn{4}{|c|}{ Older group $(n=93)$} & \multirow{2}{*}{$\begin{array}{l}\text { Age group } \\
\text { interaction }(p)\end{array}$} \\
\hline & Favorable (\%) & Unfavorable $(\%)$ & OR & $95 \% \mathrm{CI}$ & Favorable (\%) & Unfavorable $(\%)$ & OR & $95 \% \mathrm{CI}$ & \\
\hline \multicolumn{10}{|l|}{ Sex } \\
\hline Women & $78.3 \%$ & $21.7 \%$ & 1.00 & & $43.0 \%$ & $57.0 \%$ & 1.00 & & 0.80 \\
\hline Men & $75.2 \%$ & $24.8 \%$ & 1.19 & $0.70-2.02$ & $42.9 \%$ & $57.1 \%$ & 1.01 & $0.32-3.18$ & \\
\hline \multicolumn{10}{|l|}{$\mathrm{CCI}$} \\
\hline 0 & $79.3 \%$ & $20.7 \%$ & 1.00 & & $46.3 \%$ & $53.7 \%$ & 1.00 & & 0.69 \\
\hline 1 & $66.7 \%$ & $33.3 \%$ & 1.91 & $0.96-3.82$ & $41.4 \%$ & $58.6 \%$ & 1.22 & $0.49-3.04$ & \\
\hline At least 2 & $70.6 \%$ & $29.4 \%$ & 1.60 & $0.54-4.73$ & $30.0 \%$ & $70.0 \%$ & 2.01 & $0.47-8.61$ & \\
\hline \multicolumn{10}{|c|}{ Subarachnoid hemorrhage grade } \\
\hline Good-grade (WFNS I-III) & $90.7 \%$ & $9.3 \%$ & 1.00 & & $51.6 \%$ & $48.4 \%$ & 1.00 & & 0.09 \\
\hline Poor-grade (WFNS IV-V) & $51.4 \%$ & $48.6 \%$ & 9.22 & $5.04-16.85$ & $24.1 \%$ & $75.9 \%$ & 3.35 & $1.25-8.93$ & \\
\hline \multicolumn{10}{|l|}{ Acute hydrocephalus } \\
\hline No & $88.8 \%$ & $11.2 \%$ & 1.00 & & $51.2 \%$ & $48.8 \%$ & 1.00 & & 0.07 \\
\hline Yes & $62.9 \%$ & $37.1 \%$ & 4.68 & $2.61-8.41$ & $36.5 \%$ & $63.5 \%$ & 1.82 & $0.79-4.19$ & \\
\hline \multicolumn{10}{|l|}{ Thick and diffuse hemorrhage } \\
\hline No & $80.1 \%$ & $19.9 \%$ & 1.00 & & $53.8 \%$ & $46.2 \%$ & 1.00 & & 0.64 \\
\hline Yes & $73.9 \%$ & $26.1 \%$ & 1.43 & $0.84-2.42$ & $38.8 \%$ & $61.2 \%$ & 1.84 & $0.74-4.59$ & \\
\hline \multicolumn{10}{|l|}{ Intracerebral hemorrhage } \\
\hline No & $84.9 \%$ & $15.1 \%$ & 1.00 & & $45.2 \%$ & $54.8 \%$ & 1.00 & & 0.05 \\
\hline Yes & $60.4 \%$ & $39.6 \%$ & 3.69 & $2.13-6.38$ & $38.7 \%$ & $61.3 \%$ & 1.30 & $0.54-3.14$ & \\
\hline \multicolumn{10}{|c|}{ Intraventricular hemorrhage } \\
\hline No & $88.7 \%$ & $11.3 \%$ & 1.00 & & $54.3 \%$ & $45.7 \%$ & 1.00 & & 0.26 \\
\hline Yes & $67.3 \%$ & $32.7 \%$ & 3.84 & $2.08-7.06$ & $36.2 \%$ & $63.8 \%$ & 2.09 & $0.89-4.91$ & \\
\hline \multicolumn{10}{|c|}{ Aneurysm treatment modality } \\
\hline Endovascular & $75.5 \%$ & $24.5 \%$ & 1.00 & & $50.8 \%$ & $49.2 \%$ & 1.00 & & 0.04 \\
\hline Surgical & $78.6 \%$ & $21.4 \%$ & 0.84 & $0.50-1.42$ & $29.4 \%$ & $70.6 \%$ & 2.48 & $1.01-6.09$ & \\
\hline \multicolumn{10}{|l|}{ Aneurysm location } \\
\hline Anterior circulation & $79.0 \%$ & $21.0 \%$ & 1.00 & & $44.0 \%$ & $56.0 \%$ & 1.00 & & 0.42 \\
\hline Posterior circulation & $64.3 \%$ & $35.7 \%$ & 2.09 & $1.04-4.18$ & $38.9 \%$ & $61.1 \%$ & 1.24 & $0.43-3.53$ & \\
\hline
\end{tabular}

WFNS, World Federation of Neurosurgical Societies grading scale

studies support this finding [28], but our finding could also reflect a more conservative treatment approach in the elderly. Limitations of care were more common in the elderly, and their neuro-ICU episodes were shorter. In line with previous studies [29], chronic hydrocephalus requiring a shunt procedure was more often seen in the elderly patients.

There were some differences in the prognostic factors for unfavorable outcome between age groups. Overall, poorgrade SAH (WFNS IV-V) was the strongest predictive factor for unfavorable outcome in both groups. The effect seemed stronger in the younger patients, probably reflecting the small number of younger good-grade patients with unfavorable outcome. Additionally, younger SAH patients seemed to be more intolerant towards increases in intracranial pressure, either due to acute hydrocephalus or $\mathrm{ICH}$, as both showed a detrimental effect on outcome only in the younger group. Lastly, compared to endovascular treatment, surgical aneurysm closure was associated with unfavorable outcome and increased mortality in the elderly, but not in the younger SAH patients.

\section{Comparison with previous literature}

Our findings are in line with recent prospective studies on elderly SAH patients. Catapano et al. reported functional independence in $42 \%$ of elderly patients [4]. In a study by Proust et al., favorable outcome was seen in $66 \%$ of elderly goodgrade patients who had their aneurysm secured, and only in $17 \%$ of poor-grade patients [23]. Previous retrospective studies have reported a favorable outcome in $10-57 \%$ of elderly SAH patients $[10,16,21]$. Ryttlefors et al. compared the outcome between under and at least 65 -year-old SAH patients 
Table 3 Results of the multivariate logistic regression analysis without and with age group. Odds ratios (OR) with 95\% confidence interval $(\mathrm{CI})$ for unfavorable outcome at 12 months after subarachnoid hemorrhage are shown

\begin{tabular}{|c|c|c|c|c|}
\hline & \multicolumn{2}{|c|}{ Model without age group } & \multicolumn{2}{|c|}{ Model with age group } \\
\hline & OR & $95 \% \mathrm{CI}$ & OR & $95 \% \mathrm{CI}$ \\
\hline CCI score $1^{\mathrm{a}}$ & 2.60 & $1.42-4.75$ & 1.88 & $0.98-3.58$ \\
\hline CCI score at least $2^{\mathrm{a}}$ & 4.13 & $1.67-10.23$ & 3.21 & $1.23-8.37$ \\
\hline Poor-grade SAH (WFNS IV-V) & 3.24 & $1.88-5.60$ & 4.46 & $2.46-8.09$ \\
\hline Presence of acute hydrocephalus & 2.05 & $1.18-3.56$ & 2.09 & $1.17-3.74$ \\
\hline Thick and diffuse hemorrhage & 1.23 & $0.73-2.07$ & 0.91 & $0.52-1.59$ \\
\hline Intraventricular hemorrhage & 1.50 & $0.84-2.67$ & 1.53 & $0.84-2.81$ \\
\hline Intracerebral hemorrhage & 2.09 & $1.19-3.69$ & 1.99 & $1.10-3.58$ \\
\hline Posterior circulation aneurysm ${ }^{\mathrm{b}}$ & 2.31 & $1.19-4.50$ & 2.00 & $0.99-4.02$ \\
\hline Older age group & & & 5.48 & $3.02-9.96$ \\
\hline
\end{tabular}

${ }^{\text {a }}$ Compared to CCI score 0

${ }^{\mathrm{b}}$ Compare to anterior circulation aneurysm

WFNS, World Federation of Neurosurgical Societies grading scale requiring an EVD and saw favorable outcome in $43 \%$ and $24 \%$ of patients, respectively [26].

The prognostic factors for unfavorable outcome in our study were similar to those seen in large multicenter studies, with advanced age and WFNS grade affecting outcome the most $[13,24]$. Few studies have compared risk factors of poor outcome between age groups. In contrast to our findings, Degos et al. found that acute hydrocephalus treated with an EVD was associated with unfavorable outcome only in older patients [6]. The contradictory findings may reflect different indications for EVD placement.

In our study, surgical aneurysm closure was associated with unfavorable outcome and mortality at 12 months only in the older age group. In contrast, most of previous studies have found no differences between surgical and endovascular treatment in the elderly $[12,22,25]$.

\section{Strengths and limitations}

We were able to compare actively treated elderly and younger aSAH patients matched on SAH severity. If we had included all aSAH patients admitted to our hospital, the results would have favored the younger patients, as aneurysm treatment was more often withheld in the elderly. The 3:1 matching of younger patients was done for all admitted patients, but the WFNS distribution between the age groups did not differ even when considering only patients, whose aneurysm was secured.

We had extensive data regarding the patients' clinical and radiological characteristics on admission and also possible SAH complications (i.e., acute and chronic hydrocephalus, delayed cerebral ischemia). It is generally appreciated that recovery after a serious central nervous insult may take up to a year, and hence, we decided to assess our patients' functional outcome (GOS) at 12 months. Even though this was done retrospectively, we believe that the GOS classification results are reliable, as we had access to vast communal medical records.

Our study has some limitations. Due to the retrospective study design, we could not rule out that the treating clinicians' take on patients' prognosis may have affected their treatment decisions, causing a self-fulfilling prophecy. The shorter stay duration in the neuro-ICU and greater number of limitationof-care orders in the older patients could be an indication of this. Also, regarding risk factor assessment for unfavorable outcome and mortality after aSAH, this is solely a hospitalized cohort in a specialist ICU of a large tertiary university hospital, and thus, there is a risk of survival bias affecting the associations between the risk factors identified and outcome [19]. Our cohort of older patients represents previously rather healthy individuals, and our treatment results cannot be generalized to the overall population of over 70-year-olds with aSAH.

In the interaction analyses, even though we were able to include 412 patients in our study, the number of patients in some of the subgroups was small. Therefore, we considered a $p$ value of $<0.1$ indicative of a possible interaction effect, but only if the odds ratios clearly differed between age groups.

\section{Conclusions}

Overall, our study design allowed us to compare outcomes and prognostic factors between two age groups (i.e., under and at least 70 years of age) with aSAH who received active neurosurgical treatment and neurointensive care at a tertiary hospital. We found that older age is a significant, independent risk factor for poor outcome and death at 12 months. However, the most important prognostic factor for poor functional outcome and death at 12 months was WFNS score at 
admission, and this effect seemed even stronger in the younger patients. Additionally, ICH and acute hydrocephalus were associated with unfavorable outcome only in the younger patients.

Supplementary Information The online version contains supplementary material available at https://doi.org/10.1007/s00701-021-04731-4.

Funding Open access funding provided by University of Helsinki including Helsinki University Central Hospital. The study was funded by the Helsinki University Hospital Clinical Research Funds (State funding, Finland). Dr. Virta has received an independent research grant from Maire Taponen Foundation. Dr. Raj has received independent research grants from Medicinska Understödsföreningen Liv \& Hälsa and Finska Läkaresällskapet.

\section{Declarations}

Conflict of interest The authors declare no competing of interests.

Ethics approval This research study was conducted retrospectively from data obtained for clinical purposes. The local institutional research committee approved the study.

Informed consent The local institutional research committee waived the need for patient consent.

Open Access This article is licensed under a Creative Commons Attribution 4.0 International License, which permits use, sharing, adaptation, distribution and reproduction in any medium or format, as long as you give appropriate credit to the original author(s) and the source, provide a link to the Creative Commons licence, and indicate if changes were made. The images or other third party material in this article are included in the article's Creative Commons licence, unless indicated otherwise in a credit line to the material. If material is not included in the article's Creative Commons licence and your intended use is not permitted by statutory regulation or exceeds the permitted use, you will need to obtain permission directly from the copyright holder. To view a copy of this licence, visit http://creativecommons.org/licenses/by/4.0/.

\section{References}

1. Bagshaw SM, Webb SAR, Delaney A, George C, Pilcher D, Hart GK, Bellomo R (2009) Very old patients admitted to intensive care in Australia and New Zealand: a multi-centre cohort analysis. Crit Care 13(2):R45

2. Bakker MK, van der Spek RAA, van Rheenen W, Morel S, Bourcier R, Hostettler IC, Alg VS, van Eijk KR, Koido M, Akiyama M, Terao C, Matsuda K, Walters RG, Lin K, Li L, Millwood IY, Chen Z, Rouleau GA, Zhou S (2020) Genomewide association study of intracranial aneurysms identifies 17 risk loci and genetic overlap with clinical risk factors. Nat Genet 52(12): 1303-1313

3. Brookes ST, Whitely E, Egger M, Smith GD, Mulheran PA, Peters TJ (2004) Subgroup analyses in randomized trials: risks of subgroup-specific analyses; power and sample size for the interaction test. J Clin Epidemiol 57(3):229-236

4. Catapano JS, Zeoli T, Frisoli FA, Burkhardt J-K, Lawton MT (2020) Long-term independence in older patients with aneurysmal subarachnoid hemorrhage in the Barrow Ruptured Aneurysm Trial
(BRAT). World Neurosurg. https://doi.org/10.1016/j.wneu.2020. 11.139

5. Charlson ME, Pompei P, Ales KL, MacKenzie CR (1987) A new method of classifying prognostic comorbidity in longitudinal studies: development and validation. J Chronic Dis 40(5):373-383

6. Degos V, Gourraud PA, Tursis VT, Whelan R, Colonne C, Korinek AM, Clarençon F, Boch AL, Nouet A, Young WL, Apfel CC, Puybasset L (2012) Elderly age as a prognostic marker of 1-year poor outcome for subarachnoid hemorrhage patients through its interaction with admission hydrocephalus. Anesthesiology 117(6): 1289-1299

7. Drake C, Hunt W, Sano K, Kassell N, Teasdale G, Pertuiset B (1988) Report of World Federation of Neurological Surgeons Committee on a universal subarachnoid hemorrhage grading scale. J Neurosurg 68(6):985-986

8. Durand CP (2013) Does raising type 1 error rate improve power to detect interactions in linear regression models? A simulation study. PLoS One 8(8):e71079

9. Frontera JA, Claassen J, Schmidt JM, Wartenberg KE, Temes R, Connolly ES, MacDonald RL, Mayer SA (2006) Prediction of symptomatic vasospasm after subarachnoid hemorrhage: the modified fisher scale. Neurosurgery 59(1):21-26

10. Goldberg J, Schoeni D, Mordasini P, Z'Graggen W, Gralla J, Raabe A, Beck J, Fung C (2018) Survival and outcome after poor-grade aneurysmal subarachnoid hemorrhage in elderly patients. Stroke 49(12):2883-2889

11. Heo J, Hong Y, Han SS, Kim WJ, Kwon JW, Moon KW, Jeong JH, Kim YJ, Lee SH, Lee SJ (2018) Changes in the characteristics and long-term mortality rates of intensive care unit patients from 2003 to 2010: a nationwide population-based cohort study performed in the Republic of Korea. Acute Crit Care 33(3):135-145

12. Ido K, Kurogi R, Kurogi A, Nishimura K, Arimura K, Nishimura A, Ren N, Kada A, Matsuo R, Onozuka D, Hagihara A, Takagishi S, Yamagami K, Takegami M, Nohara Y, Nakashima N, Kamouchi M, Date I, Kitazono T (2020) Effect of treatment modality and cerebral vasospasm agent on patient outcomes after aneurysmal subarachnoid hemorrhage in the elderly aged 75 years and older. PLoS One. https://doi.org/10.1371/journal.pone.0230953

13. Jaja BNR, Saposnik G, Lingsma HF, Macdonald E, Thorpe KE, Mamdani M, Steyerberg EW, Molyneux A, Manoel ALDO, Schatlo B, Hanggi D, Hasan D, Wong GKC, Etminan N, Fukuda H, Torner J, Schaller KL, Suarez JI, Stienen MN (2018) Development and validation of outcome prediction models for aneurysmal subarachnoid haemorrhage: the SAHIT multinational cohort study. BMJ. https://doi.org/10.1136/bmj.j5745

14. Janssen H, Berlis A, Lutz J, Thon N, Brückmann H (2017) State of practice: endovascular treatment of acute aneurysmal SAH in Germany. Am J Neuroradiol 38(8):1574-1579

15. Jennett B, Bond M (1975) Assessment of outcome after severe brain damage. Lancet 1(7905):480-484

16. Johansson M, Cesarini KG, Contant CF, Persson L, Enblad P (2001) Changes in intervention and outcome in elderly patients with subarachnoid hemorrhage. Stroke 32(12):2845-2949

17. Korja M, Lehto H, Juvela S, Kaprio J (2016) Incidence of subarachnoid hemorrhage is decreasing together with decreasing smoking rates. Neurology 87(11):1118-1123

18. Korja M, Silventoinen K, Laatikainen T, Jousilahti P, Salomaa V, Hernesniemi J, Kaprio J (2013) Risk factors and their combined effects on the incidence rate of subarachnoid hemorrhage - a population-based cohort study. PLoS One 8(9):e73760

19. Lindbohm JV, Kaprio J, Korja M (2019) Survival bias explains improved survival in smokers and hypertensive individuals after aSAH. Neurology 93(23):e2105-e2109

20. Ohkuma H, Shimamura N, Naraoka M, Kataga T (2017) Aneurysmal subarachnoid hemorrhage in the elderly over age 75: a systematic review. Neurol Med Chir (Tokyo) 57(11):575-583 
21. Park J, Woo H, Kang DH, Kim Y (2014) Critical age affecting 1year functional outcome in elderly patients aged $\geq 70$ years with aneurysmal subarachnoid hemorrhage. Acta Neurochir (Wien) 156(9):1655-1661

22. Proust F, Bracard S, Lejeune JP, Thines L, Leclerc X, Penchet G, Bergé J, Morandi X, Gauvrit JY, Mourier K, Ricolfi F, Lonjon M, Sedat J, Bataille B, Droineau J, Civit T, Magro E, Pelissou-Guyotat I, Cebula H (2018) A randomized controlled study assessing outcome, cognition, autonomy and quality of life in over 70-year-old patients after aneurysmal subarachnoid hemorrhage. Neurochirurgie 64(6):395-400

23. Proust F, Bracard S, Thines L, Pelissou-Guyotat I, Leclerc X, Penchet G, Bergé J, Morandi X, Gauvrit JY, Mourier K, Ricolfi F, Lonjon M, Sedat J, Bataille B, Drouineau J, Civit T, Magro E, Cebula H, Chassagne P (2020) Functional outcome 1 year after aneurysmal subarachnoid hemorrhage due to ruptured intracranial aneurysm in elderly patients. Neurochirurgie 66(1):1-8

24. Rosengart AJ, Schultheiss KE, Tolentino J, Macdonald RL (2007) Prognostic factors for outcome in patients with aneurysmal subarachnoid hemorrhage. Stroke 38(8):2315-2321

25. Ryttlefors M, Enblad P, Kerr RSC, Molyneux AJ (2008) International subarachnoid aneurysm trial of neurosurgical clipping versus endovascular coiling: subgroup analysis of 278 elderly patients. Stroke 39(10):2720-2726

26. Ryttlefors M, Howells T, Ronne-Engström E, Nilsson P, Enblad P (2010) Neurointensive care is justified in elderly patients with severe subarachnoid hemorrhage - an outcome and secondary insults study. Acta Neurochir (Wien) 152(2):241-249

27. Teasdale G, Jennett B (1974) Assessment of coma and impaired consciousness. A practical scale. Lancet 304(7872):81-84

28. Wachter D, Hans F, Kreitschmann-Andermahr I, Rohde V (2011) Lower incidence of transcranial Doppler and symptomatic vasospasm after aneurysmal subarachnoid hemorrhage and aneurysm clipping in the elderly patient? Neurosurgery 69(2):261-266 discussion 266-7

29. Xie Z, Hu X, Zan X, Lin S, Li H, You C (2017) Predictors of shuntdependent hydrocephalus after aneurysmal subarachnoid hemorrhage? A systematic review and meta-analysis. World Neurosurg 106:844-860.e6

Publisher's note Springer Nature remains neutral with regard to jurisdictional claims in published maps and institutional affiliations. 